\title{
Successful Surgical Management of Giant Condyloma Acuminatum (Buschke Lowenstein Tumor) in the Urethra of a Female Patient: A Case Report
}

\author{
Michael Nordsiek Curtis Ross Michael Metro \\ Department of Urology, Albert Einstein Medical Center, Philadelphia, Pa., USA
}

\author{
Key Words \\ Extensive condyloma acuminata • Urethra • \\ Buschke lowenstein tumor
}

cal excision. We believe that further studies are needed to define this disease, identify its pathogenesis, and the most successful treatment protocol. Copyright $\odot 2014$ S. Karger AG, Basel

\begin{abstract}
The Buschke-Lowenstein tumor (BLT) is a slow-growing, locally destructive verrucous plaque that typically appears on the penis but may occur elsewhere in the anogenital region. It most commonly is considered to be a regional variant of verrucous carcinoma. It is rare but accounts for $5-24 \%$ of all penile cancers. It can also affect the perineum and other portions of the genitalia. It was first described by Buschke and Löwenstein in 1925, and is also known as giant condyloma acuminatum (GCA). Regardless of the treatment modality, careful follow-up is recommended because of the high risk of recurrence and the possibility for malignant transformation in $30-56 \%$ of patients. We present a case of a 47 -yearold Hispanic female that presented to the urology clinic for dysuria and upon work-up was found to have a GCA. GCA typically affects the penis, although the perianal region, vulva, vagina, rectum, scrotum, perineum and bladder may be involved. To date, we believe this is the only reported case of GCA in the urethra of a female patient with sparing of the bladder. This lesion was successfully removed with wide lo-
\end{abstract}

\section{KARGER}

Fax +4161306 1234

E-Mail karger@karger.ch

www.karger.com
(C) 2014 S. Karger AG, Basel

$1015-9770 / 14 / 0081-0049 \$ 38.00 / 0$

Accessible online at:

www.karger.com/cur

\section{Introduction}

The Buschke-Lowenstein tumor (BLT) is a rare disease but affects the genitalia in sometimes remarkable fashion. It was first described by Buschke and Löwenstein in 1925, and is also known as giant condyloma acuminatum (GCA) [1]. This lesion has malignant behavior as it typically invades local tissues and lacks spontaneous resolution. Despite its slow growing local invasive mature, GCA is rarely metastatic, but it has a high rate of recurrence [2]. However, reports describe histologic transformation of GCA to invasive squamous cell carcinoma in $8.5-23.8 \%$ of cases [3]. Mortality rates from GCA have been reported at 20-30\% [4].

GCA has been shown to have an association with HPV types 6 and 11 (occasionally types 16 and 18) [5]. Poor hygiene, local irritation, immunosuppression, HIV infection, and anoreceptive intercourse have been shown to be risk factors for GCA $[2,6,7]$. The epidemiology of

Michael Nordsiek

Albert Einstein Medical Cente 5501 Old York Rd

Philadelphia, PA 19141 (USA)

E-Mail mfnord10@gmail.com 
GCA is more common in males at a 3.5:1 ratio and two thirds of cases are reported in patients under 50 years old [7]. Fewer than 60 cases of anorectal or perineal GCA and fewer than 15 bladder GCA cases have been reported $[8,9]$.

We report a female patient with GCA involving only the distal urethra and urethral meatus while sparing the bladder.

\section{Case Report}

A 47-year-old heterosexual Hispanic female presented to the urology clinic for dysuria and urinating with a split stream. These symptoms had been present for approximately 4 weeks. Most recently, she also noted extreme headaches, hematuria, and cloudy, foul-smelling urine.

She had a history of a urethral stricture, for which she received 2 urethral stricture dilations by another urologist, the most recent procedure was about 6 years ago. She was then lost to follow-up, and had not required the services of a urologist until her most recent symptomatology.

She was otherwise healthy, and besides her history of urethral stricture she denied all other past medical or surgical history. She was not on any regular medications or had any known allergies. She was a social drinker, and quitted smoking cigarettes 5 years ago.

On physical examination, a large, irregular, circumferential, red-pigmented, verrucous plaque was found extending out of the urethral meatus. The mass did not appear to extend proximally into the urethra, but a 16-French flexible cystoscope could not be passed in the clinic due to the obstruction. She had no palpable lymphadenopathy, and the rest of her physical exam was benign.

Her complete blood count and vitals were within normal limits. Her urinalysis was suggestive of an infection, so a culture was obtained, and she was placed on 500mg of ciprofloxacin taken twice a day for 7 days. Because of her complaint of hematuria, urine cytology was also obtained, which ultimately was negative.

Risks and benefits of urethral mass excision were discussed with the patient. The patient underwent a complete physical exam under anesthesia, cystourethroscopy, urethral dilatation, excision of her urethral mass, and Foley catheter placement. Upon dilation of her urethra using an 18-French dilator, a pancystourethroscopy revealed the mass that extended from the urethral meatus (fig. 1). The proximal urethra and bladder were free of lesions.

A piece of the mass was then removed and sent to pathology for frozen section. The pathologist reported the specimen as having squamous mucosa with dysplasia and viral cytopathic effect, without evidence of frank carcinoma. The decision was them made to excise this mass as if it were a urethral caruncle. The mass was excised with Metzenbaum scissors and toothed forceps to the level of normal appearing tissue on the urethra and the mucosa. The excised mass measured approximately $3.2 \times 1.8 \times 0.7 \mathrm{~cm}$. Closure was carried out in an interrupted fashion using 3-0 Vicryl suture around the entire circumference of the urethra (fig. 2. a).

On gross examination, the entire mass had been excised (fig. 2 . b). A piece of gauze was then placed around the tip of a 16-French Council tip Foley catheter at the level of the urethral meatus. She

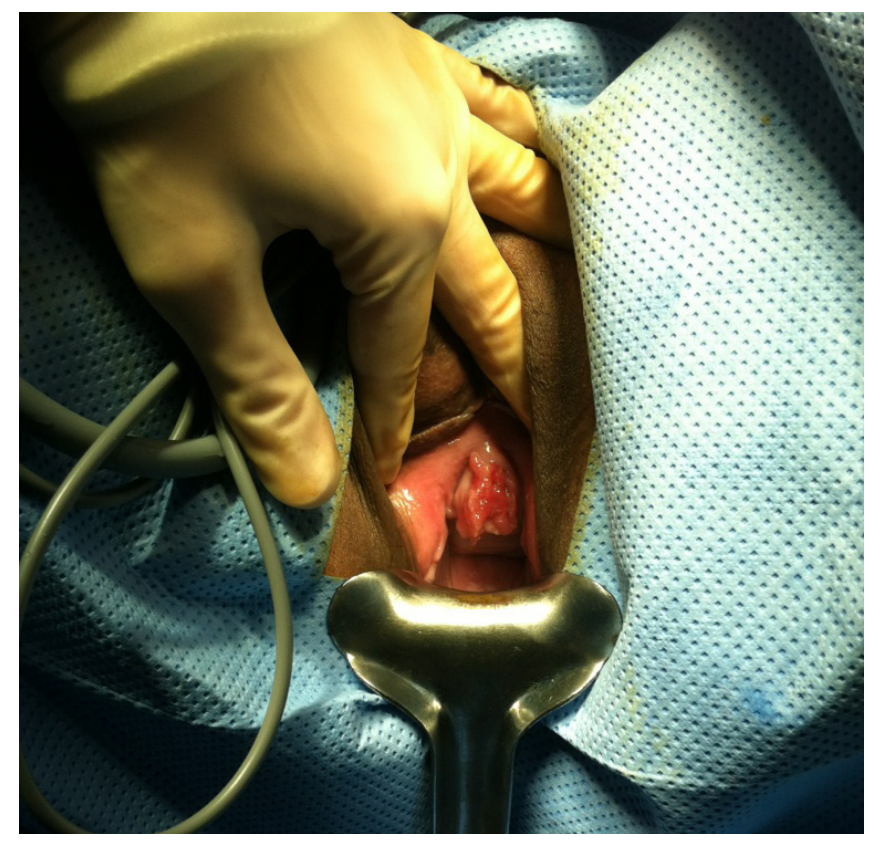

Fig. 1. Preoperative appearance of the patient with an irregular mass protruding from urethral meatus.

tolerated the procedure well and was discharged home that same day with instructions to follow-up in the office for removal of the catheter in 2 weeks.

Histologically, the mass showed changes typical of GCA with high-grade squamous intraepithelial and severe squamous dysplasia. Surgical margins were negative. Also present was epidermal hyperplasia, hyperkeratosis, and parakeratosis. The urine cytology showed benign squamous and urothelial cells.

The lesion was treated with conservative, local surgery. When the patient was scheduled for follow-up, she did develop neither local recurrence nor distant metastasis. Her catheter was removed in one week, and she was able to pass her void trial. On subsequent follow-up about three weeks after the procedure, she reported, "... now I have the strongest stream that I can remember."

\section{Discussion}

The presented case shows a GCA in a female patient in an unusual location. GCA typically affects the penis, although the perianal region, vulva, vagina, rectum, scrotum, perineum and bladder may be involved [10]. To date, we believe this is the only reported case of GCA in the urethra of a female patient with sparing of the bladder. Because of the rarity of this condition, its pathogenesis and etiology are debated. GCA is classified as a verru- 

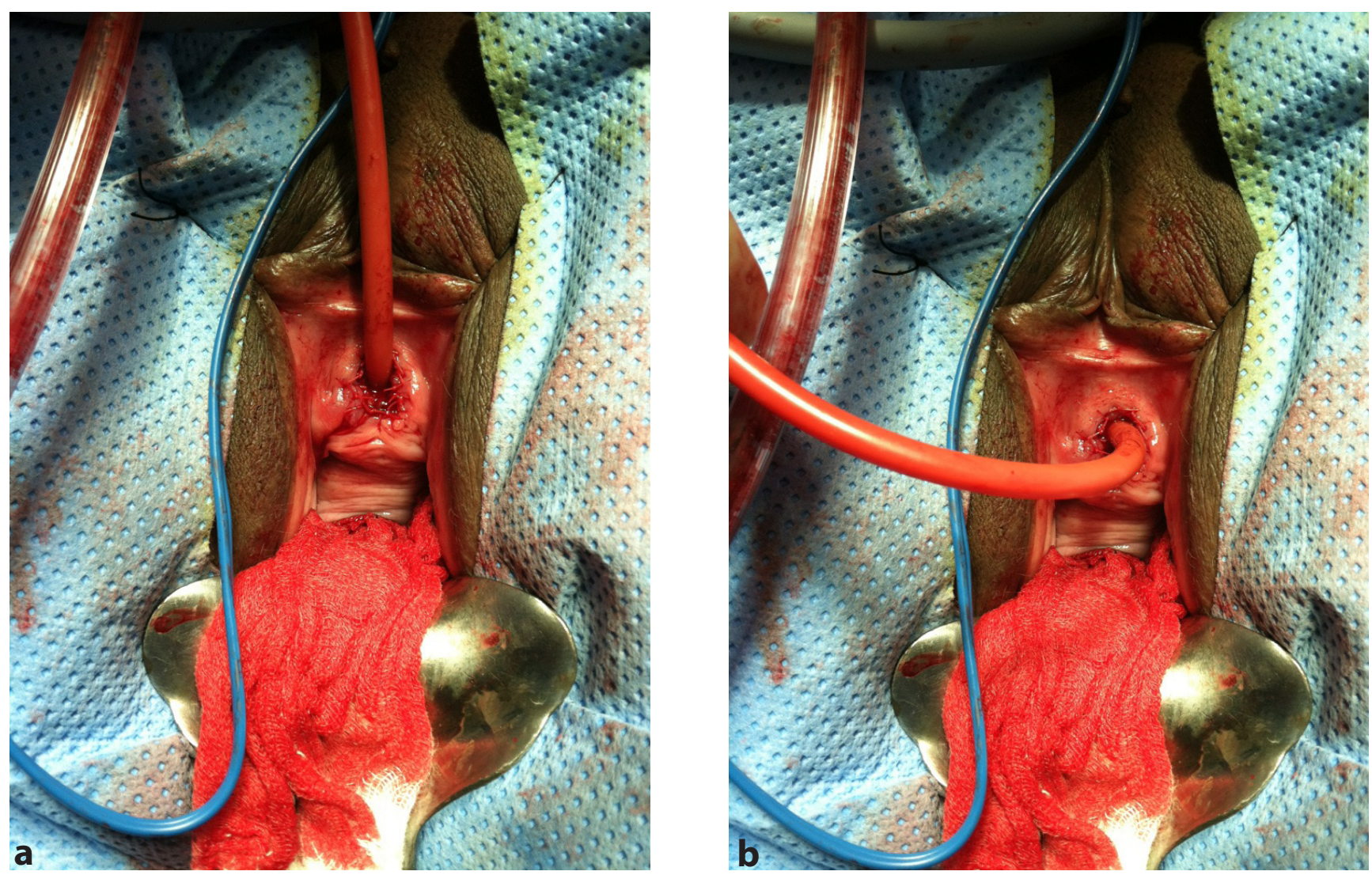

Fig. 2. a Excision of mass; b Successful reconstruction and closure of the urethra meatus.

cous carcinoma, when it is present in the genitoanal region, it is termed a Buschke-Lowenstein tumor $[11,12]$. Some authors believe that it represents a transition between condyloma acuminatum and squamous cell carcinoma [2]. Histologically, GCA has a benign appearance; which resembles that of condyloma acuminatum. When GCA has deep infiltration and locally advanced staging, some authors regard GCA as a verrucous carcinoma, a low grade squamous cell carcinoma with minimal metastatic risk [5].

Likewise, there are many opinions for the treatment of GCA. Most authors agree that wide local excision of the lesion is the most suitable treatment for GCA. Surgery alone has been reported to have a disease-free status in $45.5 \%$ in patients $[13,14]$. In our female patient, the exophytic mass was removed by surgical excision with negative surgical margins.

A variety of nonsurgical treatments exist. Case reports exist showing the application of topical agents such as podophylline, 5-fluorouracil, and bleomycin; however the results appear to have mixed success [15]. Because of the theorized viral etiology of the lesion, intralesional interferon- $2 b$ has been used with moderate results [16]. Others have successfully treated using the immune-modulator, imiquimod, in combination with systemic acitretin and local excision [17]. Acitretin is a retinoid that also has immunomodulating and pro-apoptotic properties.

Additionally, GCA has been treated successfully using carbon dioxide laser vaporization for lesions either after imiquimod treatment [18], or after initial surgical excision [19].

Regardless of the treatment modality, careful follow-up is recommended because of the high risk of recurrence and the possibility for malignant transformation. Recurrence rates have been reported as high has 50\% and these patients typically have a poorer prognosis [2].

We, along with other authors, believe that further studies are needed to define this disease, identify its pathogenesis, and the most successful treatment protocol [8]. 


\section{References}

1 Buschke A, Lowenstein L: Über carcinomahnliche Condylomata Acuminata des Penis. Klin Wochenschr 1925;4:726-728.

2 Creasman C, Haas PA, Fox TA Jr, Balazs M: Malignant transformation of anorectal giant condyloma acuminatum (Buschke-Löwenstein tumor). Dis Colon Rectum 1989;32:481-487.

3 Valenzuela N, Barnadas MA, Matias-Guiu X, Curell R, de Andres L, Alomar A: Lethal perianal Buschke-Loewenstein tumor in a female patients with AIDS. Dermatology 2004;208:349-350.

4 Chu QD, Vezeridis MP, Libbey NP, Wanebo HJ: Giant condyloma acuminatum (BuschkeLowenstein tumor) of the anorectal and perianal regions-analysis of 42 cases. Dis Colon Rectum 1994;37:950-957.

5 Schwartz RA: Verroucous carcinoma of the skin and mucosa. J Am Acad Dermatol 1995;32:1-21.

6 Boshart M, zur Hausen H: Human papillomavirus in Buschke-Loewenstein tumors: physical state of the DNA and identification of a tandem duplication in the noncoding region of a human papillomavirus 6 subtype. J Virol 1986;58:963-966.

7 Nash G, Allen W, Nash S: Atypical lesions of anal mucosa in homosexual men. JAMA 1986;256:873-876.
8 Trombetta LJ, Place RJ: Giant condyloma acuminatum of the anorectum: trends in epidemiology and management: report of a case and review of the literature. Dis Colon Rectum 2001;44:1878-1886.

9 Ginsberg PC, Williams JJ, Klaus RL: Bilateral ureteral obstruction secondary to condylomata acuminata of the urinary bladder. J Am Osteopath Assoc 1989;89:69-72.

10 Gilbert SM, Lambert SM, Weiner D: Extensive condylomata acuminata of the penis: medical and surgical management. Infect Urol 2003;16:65-76.

11 Steffen C: The men and the eponym-Abraham Buschke and Ludwig Lowenstein: giant condyloma (Buschke-Lowenstein). Am J Dermatopathol 2006;28:526-536.

12 Martin JM, Molina I, Monteagudo C, Marti N, Lopez V, Jorda E: Buschke-Lowenstein tumor. J Dermatol Case Rep 2008;4:60-62.

13 Klein N, Jasch K, Kimmritz J, Hermes B, Harth W: Operative therapy of a monstrous Buschke-Lowenstein tumor. Dermatology 2007;215:264-265.

14 Renzi A, Giordano P, Renzi G, Landolfi V, Del Genio A, Weiss EG: Buschke-Lowenstein tumor successful treatment by surgical excision alone: a case report. Surg Innov 2006;13:69-72.
15 Gholam P, Enk A, Hartschuh W: Successful surgical management of giant condyloma acuminatum (Buschke-Lowenstein tumor) in the genitoanal region: a case report and evaluation of current therapies. Dermatology 2009;218:56-59.

16 Geusau A, Heinz-Peer G, Volc-Platzer B, Stingl G, Kirnbauer R: Regression of deeply infiltrating giant condyloma (Buschke-Löwenstein tumor) following long-term intralesional interferon alfa therapy. Arch Dermatol 2000;136:707-710.

17 Erkek E, Basar H, Bozdogan O, Emeksiz MC: Giant Condyloma acuminata of Buschke-Lowenstein: successful treatment with a combination of surgical excision, oral acitretin and topical imiquimod. Clin Exp Dermatol 2009;34:366-368.

18 Heinzerling LM, Kempf W, Kamarashev J, Hafner J, Nestle FO: Treatment of verrucous carcinoma with imiquimod and $\mathrm{CO} 2$ laser ablation. Dermatology 2003;207:119-122.

19 Perisic Z, Lazic JP, Terzic B, Perisic S, Rasic $\mathrm{R}$ : Condylomata gigantea in anal and perianal region: surgical and $\mathrm{CO} 2$ treatment. Arch Gynecol Obstet 2003;267:263-265. 